\title{
Comparison Study between Posterior Fossa Decompression with Duroplasty and Posterior Fossa Decompression without Duroplasty, in 20 Cases of Chiari I Malformation
}

\author{
Ahmed M. Elshanawany \\ Department of Neurosurgery, Faculty of Medicine, Assiut University, Assiut, Egypt \\ Email: aelshanawany@ymail.com
}

How to cite this paper: Elshanawany, A.M. (2018) Comparison Study between Posterior Fossa Decompression with Duroplasty and Posterior Fossa Decompression without Duroplasty, in 20 Cases of Chiari I Malformation. Open Journal of Modern Neurosurgery, 8, 353-359.

https://doi.org/10.4236/ojmn.2018.84030

Received: June 7, 2018

Accepted: August 13, 2018

Published: August 16, 2018

Copyright $\odot 2018$ by author and Scientific Research Publishing Inc. This work is licensed under the Creative Commons Attribution International License (CC BY 4.0).

http://creativecommons.org/licenses/by/4.0/

(c) (i) Open Access

\begin{abstract}
Introduction: Chiari malformation Type I (CM-I) is typically defined as descent of the caudal tip of cerebellar tonsils at least $5 \mathrm{~mm}$ below the foramen magnum. The incidence of the malformation is not exactly known. Treatment of Chiari I malformation is debatable. Some advocate posterior fossa decompression (PFD) with duroplasty and others advocate posterior fossa decompression only without duroplasty. Aim of the Study: To compare the outcomes of patients who undergoing PFD with duroplasty and PFD without duroplasty, in Chiari I malformation. Patients and Methods: In the period between "January 2015-June 2016", a prospective study was conducted involving 20 patients complaining of headache, motor and/or sensory affection secondary to Chiari I malformation. These patients were randomly divided into 2 groups. The first one had PFD with duroplasty and the other will have PFD without duroplasty. All patients had chiari one malformation in form of tonsillar herniation and cervical or cervico-dorsal syrinx. The average follow-up period was 9 months. Results: Over $90 \%$ of patients had a good clinical outcome, with improvement or resolution of their symptoms at last follow-up. There were no major complications. The mean length of hospital stay was 2.0 days. There was no perioperative death or neurological deterioration. The use of duroplasty was significantly associated with presence of complications and longer duration of hospital stay. Conclusion: PFD without duroplasty in cases of chiari I malformation carries a good results as well as PFD with duroplasty with lower risk of complications.
\end{abstract}

\section{Keywords}

Chiari Malformation, Non-Dural Opening Procedure, Suboccipital Decompression, Duroplasty, Outcomes 


\section{Introduction}

Chiari malformation type I (CM-I) is a congenital disease characterized by decent of the caudal tip of cerebellar tonsil and crowding in the craniocervical junction area, which was first described by Hans Chiari over one century ago [1].

Generally, about 50\% - 70\% CM-I cases are associated with syringomyelia (SM), which will slowly lead to chronic and sometimes irreversible myelopathy [2] [3]. Although many individuals with CM-I are asymptomatic, the malformation can cause headaches, cerebellar ataxia, ocular disturbances, spasticity or lower cranial nerve affection [4]. Since many cases of CM-I are asymptomatic, prevalence may not be accurate. However, a retrospective investigation of brain magnetic resonance images (MRIs) reported that the prevalence of CM-I was one case in 1280 individuals [4]. Surgery is the only way to cure this disease. Patients with syringomyelia have a poorer outcome with surgery, compared with those without syringomyelia [5].

In the present report, we review our experience with the treatment of CM-I in patients who underwent suboccipital bony decompression with or without duroplasty.

\section{Patients and Methods}

A prospective study was conducted between "January 2015-June 2016". This study includes 20 patients (as we are large referral centre covering most of south of Egypt receiving patients from big population area these criteria allow large number of cases) who were admitted to the Neurosurgery department, Assuit University Hospital, Faculty of Medicine, Assuit, Egypt, and performed surgery for treatment of Chiari I malformation. We included patients that had chiari malformation in form of tonsillar herniation and cervical or cervico-dorsal syrinx. These patients were randomly divided into 2 groups, the first one had posterior fossa decompression associated with duroplasty (group 1) and the second group had PFD only without duroplasty (group 2). We excluded those patients that had chiari malformation in form of tonsillar herniation without syringomyelia.

All patients in both groups had complete medical history and complete neurological examination. Complete basal laboratory investigations were done. Preoperative radiological imaging in the form of computed tomography (CT) of the brain and magnetic resonance imaging (MRI) of the brain and craniocervical junction were done (Figure 1).

All patients underwent decompressive sub occipital craniectomy extending at least $2 \mathrm{~cm}$ above the foramen magnum, with atlas laminaectomy. Ten patients then underwent duroplasty using fascia lata or pericranium graft. Patients were chosen for duroplasty randomly.

Post-operative clinical results are rated as excellent, good, fair and poor [6]. Results were considered excellent if all the patient's preoperative neurological 


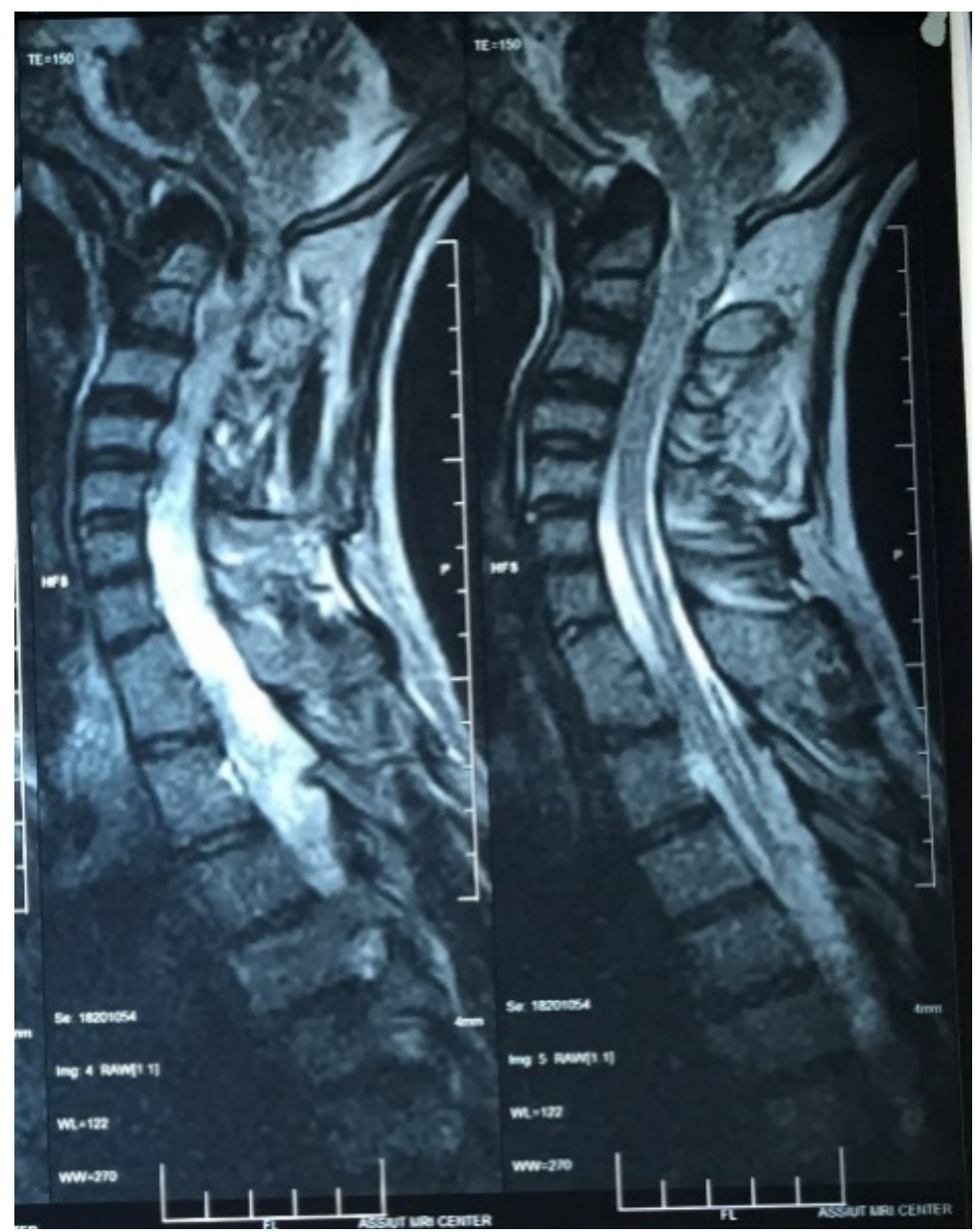

Figure 1. MRI brain and craniocervical junction revealed picture of Chiari I malformation in the form of cerebellar tonsils herniation below foramen magnum with syrinx.

symptoms are relieved and he is able to return to his normal daily activities. Good if partial improvement is achieved regarding preoperative symptoms but the patient is able to return to his normal daily activities. Fair if partial improvement is achieved but the patient is dependent or assisted for his daily activities and poor results are defined as worsening of the neurological condition and level of conscious or even death.

This is a clinical data analysis. All patients' confidential data were kept. We follow all ethical aspects regards ethical committee of faculty of medicine, Assiut university.

\section{Results}

We had 20 patients in our study their ages are ranging from 18 to 42 years (28.9) (Table 1). We had 12 males (60\%) and 8 females (40\%) (Table 1). We found that headache was the most common complaint in all patients representing about $70 \%$ of all clinical symptoms followed by neck pain and motor deficit (Table 2). 
Table 1. Summary of demographic data of two groups.

\begin{tabular}{ccc}
\hline & Group 1 & Group 2 \\
\hline Sex & Males: 7 & Males: 5 \\
& Females: 3 & Females: 5 \\
Mean of age & 25.8 years & 29.9 years \\
\hline
\end{tabular}

Table 2. Clinical summary of the patients.

\begin{tabular}{ccccc}
\hline Clinical picture & No. of cases & Group 1 & Group 2 & $\%$ \\
\hline Neck pain & 8 & 4 & 4 & 40 \\
Weakness & 5 & 3 & 2 & 25 \\
Ataxia & 3 & 1 & 2 & 15 \\
Chocking & 3 & 2 & 1 & 15 \\
Headache & 14 & 5 & 9 & 70 \\
Numbness & 0 & - & - & 0
\end{tabular}

Postoperative complications were found in 3 patients in the form of CSF leak in the group of patients who underwent opening of the dura and duroplasty, with no major complications reported in patients who underwent PFD Only (Table 3).

Regarding postoperative outcome, 8 out of 10 patients with PFD only had excellent outcome with complete improvement of their symptoms with no major complications and one patient had good outcome and another patient had fair outcome and needed reoperation with duroplasty. On the other hand 3 out 10 patients who underwent PFD with duroplasty had good outcome due to the presence of CSF leak which affect the quality of outcome and prolonged the hospital stay of these patients (Table 4). Those patients were treated by additional suture and repeated lumber puncture.

\section{Discussion}

Chiari I malformation is defined as downward descent of caudal tip of cerebellar tonsil and crowding in the craniocervical junction area [1] [7] [8]. A hypothesis regarding the pathogenesis of CM-I is that the posterior fossa and hindbrain structures are dislocated into the spinal canal after birth due to small posterior cranial fossa volume which is caused by the retarded development of the occipital bone during the embryonic period [9].

Other types of Chiari malformation includes:

Chiari Malformation Type II becomes symptomatic in infancy or early childhood as it is more severe than Type I. It is characterized by the caudal displacement of the medulla, fourth ventricle and cerebellar tonsils into the cervical spinal canal. Chiari Malformation Type II commonly occurs in children with Spina Bifida or Myelomeningocele [7] [8]. 
Table 3. Summary of postoperative complications in both group.

\begin{tabular}{ccc}
\hline Complications & PFD only. & PFD with duroplasty \\
\hline CSF leak & 0 & 3 \\
Weakness & 0 & 0 \\
Cranial nerve palsy & 0 & 0 \\
Hydrocephalus & 0 & 0 \\
\hline
\end{tabular}

Table 4. Showing summary of postoperative outcome in both group.

\begin{tabular}{ccc}
\hline Outcome & PFD only. & PFD with duroplasty \\
\hline Excellent & 8 & 7 \\
Good & 1 & 3 \\
Fair & 1 & 0 \\
Poor & 0 & 0 \\
\hline
\end{tabular}

Chiari Malformation Type III is very rare. This type is characterized by a portion of the cerebellum and brainstem pushing out through an occipital encephalocele. An encephalocele is an abnormal opening in the back of the skull. This leads to a bony defect similar to spina bifida. The meninges or brain tissue herniates outside the skull. Chiari Malformation Type III has a high and early mortality rate or severe neurological deficits in surviving patients [7] [8].

Chiari Malformation Type IV is the most severe and rarest form with an extremely high mortality rate in infancy. The cerebellum does not develop normally during pregnancy. Other malformations of the brainstem may also be present [7] [8].

Chiari Malformation Type 0 is characterized by an alteration in the cerebrospinal fluid hydrodynamics at the level of the foramen magnum not necessarily with cerebellar tonsil herniation. Patients with this type of Chiari Malformation often develop syringomyelia. Some physicians do not consider Type 0 to be a Chiari Malformation because there is no cerebellar tonsil herniation [7].

However, the pathogenesis of syringomylia remains unclear. The 3 main theories which try to explain the formation of syringomylia are Gardner's hydrokinetics, Oldfield's CSF and spinal substance penetration and Williams' intracranial and intraspinal pressure dissociation [10]. Partial obstruction in the foramen magnum area blocks the normal circulation of CSF which is a major factor in the development and progression of syringomylia [10].

Suboccipital craniectomy essential to relieve the bony compression at the craniocervical junction [11]. However, no agreement on safety and usefulness of additional procedures, such as duroplasty, obex plugging or syringosubarachnoid shunting [12]. Also there is no agreement about the value of tonsillar resection. There is no direct neurological deficit that has been demonstrated as a result of tonsillar resection [13].

In our study, 8 out of 10 patients who had PFD only had complete improve- 
ment of their symptoms with no major complications. This is in agreement with study made by Benjamin et al. in 2015 who recommended PFD only in patients with CM-I if there is no additional syrinx and more than $90 \%$ of the patients in this study improved completely [14].

CSF leaks reported in three cases and secondary stitches resolved the leaks. The subgaleal fluid collections that developed after surgery were also resolved conservatively with tight bandage.

We found no significant difference between outcomes in patients with PFD only $80 \%$ and those with duroplasty $70 \%$. This is in agreement with Gurbuz et al. who found no significant difference between improvement in the duroplasty group (81\%) and the non-duroplasty group (61.1\%) in a series on thirty-nine cases of CM-1 with and without syringomyelia [14]. Despite Gurbuz et al. suggest PFD with duroplasty in patients with syringomyelia or whom symptoms duration were less than 36 months [14].

On the other hand Benjamin et al. recommended PFD without opening the dura for the vast majority of symptomatic patients with CM-I. He recommended opening the dura in patients with rapidly progressive neurological deficits, rapidly progressive scoliosis with syrinx [15].

Patients who underwent PFD only had an average hospital stay shorter than who underwent PFD with duroplasty. Mutchnick et al. found that patients treated with PFD and duroplasty had average hospital stays of 4.0 days, whereas that for patients treated with PFD was 2.7 days [16].

\section{Conclusion}

We found no significant difference in the outcome in patients who underwent PFD only and those who underwent PFD and duroplasty. We recommend PFD with duroplasty in patients with syrinx. Patients with PFD and duroplasty are associated with longer average hospital stay and at higher risk of complications.

\section{Acknowledgements}

The author would like to thank Prof. Ahmed Al-Gheriany for his valuable instructions, fruitful recommendations and generous guidance. Also, I would like to thank Dr. Osama Ramadan for his help and effort.

\section{References}

[1] Chiari, H. (1891) Uber Veranderungen des Kleinhirns infolge von Hydrocephalie des Grosshirns. Deutsche medizinische Wochenschrift, 17, 1172-1175. (in German) https://doi.org/10.1055/s-0029-1206803

[2] Armonda, R.A., Citrin, C.M., Foley, K.T. and Ellenbogen, R.G. (1994) Quantitative Cine Mode Magnetic Resonance Imaging of Chiari I Malformations. An Analysis of Cerebrospinal Fluid Dynamics. Neurosurgery, 35, 214-224. https://doi.org/10.1227/00006123-199408000-00006

[3] Goel, A. and Desai, K. (2000) Surgery for Syringomyelia. An Analysis Based on 163 Surgical Cases. Acta Neurochirurgica, 142, 293-302. 
https://doi.org/10.1007/s007010050038

[4] Stover, L.J., Bergan, U., Nilsen, G. and Sjaastad, O. (1993) Posterior Cranial Fossa Dimensions in the Chiari I Malformation. Relation to Pathogenesis and Clinical Presentation. Neuroradiology, 35, 113-118. https://doi.org/10.1007/BF00593966

[5] Matsumoto, T. and Symon, L. (1989) Surgical Management of Syringomyelia. Current Results. Surgical Neurology, 32, 253-256. https://doi.org/10.1016/0090-3019(89)90227-9

[6] Elsaid, A and El-Borady, M. (2015) Posterior Fossa Decompression with Duroplasty for Treatment of Chiari Type I Malformation: Surgical Technique, Clinical and Radiological Outcome. Egyptian Journal of Neurosurgery, 30, 285-290.

[7] Ninds.nih.gov. (2015) Chiari Malformation: Fact Sheet. http://www.ninds.nih.gov/disorders/chiari/detail_chiari.htm

[8] Perkin, G.D., Miller, D.C., Lane, R.J.M., Patil, M.C. and Hochberg, F.H. (2011) Atlas of Clinical Neurology. 3rd Edition, Elsevier, USA, 267-268.

[9] Furtado, S.V., Thakre, D.J., Venkatesh, P.K., Reddy, K. and Hegde, A.S. (2010) Morphometric Analysis of Foramen Magnum Dimensions and Intracranial Volume in Pediatric Chiari I Malformation. Acta Neurochirurgica (Wien), 152, 217-221. https://doi.org/10.1007/s00701-009-0480-5

[10] Park, Y.S., Kim, D.S., Shim, K.W., Kim, J.H. and Choi, J.U. (2009) Factors Contributing Improvement of Syringomyelia and Surgical Outcome in Type I Chiari Malformation. Child s Nervous System, 25, 453-459. https://doi.org/10.1007/s00381-008-0763-9

[11] Romero, F.R. and Pereira, C.A. (2010) Suboccipital Craniectomy with or without Duraplasty-What Is Best Choice in Patients with Chiari Type 1 Malformation. Arqneuropsiquiatr, 68, 623-626. https://doi.org/10.1590/S0004-282X2010000400027

[12] Munshi, I., Frim, D., Stine-Reyes, R., Weir, B.K., Hekmatpanah, J. and Brown, F. (2000) Effects of Posterior Fossa Decompression with and without Duraplasty on Chiari Malformation-Associated Hydromyelia. Neurosurgery, 46, 1384-1390. https://doi.org/10.1097/00006123-200006000-00018

[13] Lazareff, J.A., Galarza, M., Gravori, T. and Spinks, T.J. (2002) Tonsillectomy without Craniectomy for the Management of Infantile Chiari I Malformation. Journal of Neurosurgery, 97, 1018-1022. https://doi.org/10.3171/jns.2002.97.5.1018

[14] Kennedy, B.C., Kelly, K.M., Phan, M.Q., Bruce, S.S., McDowell, M.M., Anderson, R.C.E. and Feldstein, N.A. (2015) Outcomes after Suboccipital Decompression without Dural Opening in Children with Chiari Malformation Type I. Journal of Neurosurgery Pediatrics, 16, 150-158. https://doi.org/10.3171/2014.12.PEDS14487

[15] Gurbuz, M.S., Karaaslan, N., Caliskan, T., Unal, E. and Berkman, M.Z. Comparison of the Surgical Results for Foramen Magnum Decompression with and without Duraplasty in Chiari Malformation Type 1. Turkish Neurosurgery, 25, 419-424.

[16] Mutchnick, I.S., Janjua, R.M., Moeller, K. and Moriarty, T.M. (2010) Decompression of Chiari Malformation with and without Duraplasty: Morbidity versus Recurrence. Journal of Neurosurgery. Pediatrics, 5, 474-478. https://doi.org/10.3171/2010.1.PEDS09218 